\title{
Phytochemical Analysis and Standardization of Pedalium murex Linn. Extract through HPLC Methods
}

\author{
Renuka Mahajan, Prakash Itankar \\ Department of Pharmaceutical Sciences, Rashtrasant Tukadoji Maharaj Nagpur University, Nagpur, Maharashtra, INDIA.
}

\begin{abstract}
Aim: The study aims screening of phytochemicals and standardization of extract of Pedalium murex Linn. fruits. Methods: The extraction was carried out by maceration technique using $70 \%$ ethanol and $30 \%$ water. The aqueous ethanolic extract obtained was estimated for total phenolic and flavonoid content against the standard gallic acid and quercetin. Liquid -liquid partitioning method using solvents n-hexane, chloroform, ethylacetate provided the different fractions of aqueous ethanolic extract. Standardization was done with highly sensitive, accurate, easy and cost effective high performance liquid chromatographic method. Results: The preliminary phytochemical screening of aqueous ethanolic extract of $P$. murex fruits revealed the presence of alkaloids, saponins, tannins, flavonoids, sugar, glycosides, phenols and sterols. The total phenolic content determined using linear regression equation $(y=$ $0.0123 x-0.0096 R^{2}=0.9962$ ) was found to be $27.1 \pm 0.72 \mathrm{mg} / \mathrm{g}$ equivalent of gallic acid while the flavonoid content was expressed as $17.6 \pm 0.79 \mathrm{mg} / \mathrm{g}$ equivalent of quercetin. The mother extract and the aqueous fraction revealed peaks complementary with the chromatogram of standard quercetin addressing presence of quercetin. Conclusion: The study helped in developing the phytochemical profile of the extract and the standardization performed in the study confirmed the presence of quercetin in the mother extract and fractions.

Key words: Maceration, Phytochemical screening, Liquid- liquid partitioning, Phenolic content, Flavonoid content, HPLC.
\end{abstract}

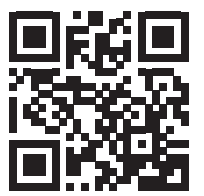

www.ijnponline.com

DOI : 10.5530/ijnp.2021.1.7

\section{INTRODUCTION}

Various health ailments have been traditionally treated using medicinal plants since ancient times. Plants are the reservoir of naturally occurring bioactive compounds for drug discovery. These compounds serve as remedy for variety of diseases and are of extreme interest in modern therapeutics. ${ }^{[1]}$ Pedalium murex L. commonly designated worldwide as large caltrops has been consistently evaluated, past five decades, for its biological activity and medicinal properties. The plant belonging to the family Pedaliaceae is also called as Gokshura, Gokantaka, Bara gokhru, Khaar-e-kkhasak, Peru neranji and with few more names in other languages. It is commonly found throughout India especially in Southern coastal region i.e. Kokan, Gujrat, Kathiawar, Ceylon, Peninsula and Deccan. The plant is also distributed over Pakistan, Sri Lanka, Mexico and Africa. ${ }^{[2]}$ It is an annual, branched, succulent herb about 15-40 cm in height with spiny, four angled brownish colored fruits. Leaves are ovate oblong, simple, opposite, fleshy, glabrous with minute scales on lower sides. ${ }^{[3]}$ The plant flowers from September to November and fruits are observed in period November to January. Ayurvedic formulations use gokshura fruits for treatment of urinary disorders. ${ }^{[4]}$ Traditionally, the admixture produced from stem, fruits and /or leaves are effective as demulcent and diuretic. The plant is also used in urinary disorders like incontinence of urine, dysuria, gonorrhea and spermatorrhoea. It is believed to relieve strangury and dissolve calculi. Leaves are largely used to heal ulcers and as curry in splenic enlargement. [5,6] Decoction of roots is used as antibilious. So far, antimicrobial, anti-bacterial, antioxidant, anti-inflammatory, nephroprotector, antihyperlipidemic, antidiabetic, antiulcer and aphrodisiac activities have been studied on the plant. ${ }^{[7]}$ The glycosides and glucuronides like dinatoin and diosmetin along with several flavonoids from leaves and flowers were isolated. The steroidal content from petroleum ether extract has found to possess fertility enhancing properties. Moreover, triacotanyl dotriacontanoate, $2^{\prime}, 4^{\prime}, 5^{\prime}$-trihydroxy 5,7-dimethoxy flavones, tetratriacontanyl octacosanoate and heptatriacontan-4- one from fruits has been isolated previously. ${ }^{[8]}$ The fruits are found to be rich in soluble proteins, sapogenins and flavonoids. ${ }^{[1]}$ The plant being loch of naturally occurring bioactive metabolites, the work was undertaken to analyze the phytochemical profile and develop fingerprinting of hydro alcoholic extract and fractions for standardization of extract.

\section{METHODS}

\section{Plant material}

The fruits were collected from local market and authenticated by Dr. N. Dongarwar, Professor, Department of Botany, R.T.M. Nagpur University, Nagpur. The specimen voucher number is 1078 .

\section{Extraction}

The dried fruits were subjected to size reduction. The coarsely powdered drug (500 g) was macerated for $48 \mathrm{hr}$ in aqueous ethanolic solvent (70\% ethanol: $30 \%$ water) with intermediate stirring. The obtained extract was filtered by using Whatman filter paper no. 42 and concentrated using a rotary vacuum evaporator to get the semisolid residue. ${ }^{[9]}$ The percent yield was calculated as: Weight of extract / Weight of drug taken $\times 100$ 


\section{Phytochemical analysis}

Battery of chemical tests was performed to ascertain presence of phytoconstituents. The hydroalcoholic extract was scrutinized for the presence of cardiac glycosides, alkaloids, flavonoids, steroids, glycosides, saponins, phenols and tannins according to standard procedures. ${ }^{[10]}$

\section{Quantitative estimation Estimation of total phenolic content}

Folin Ciocalteau method was used for determination of phenolic content. Briefly, stock solution was prepared by dissolving $100 \mathrm{mg}$ of extract, in $100 \mathrm{~mL}$ of methanol. This was further diluted 3 times and 1 $\mathrm{mL}$ of this resultant solution was exposed to $8 \mathrm{~mL}$ of methanol and 0.5 $\mathrm{mL}$ of $2 \mathrm{~N}$ Folin Ciocalteau reagent (FCR), along with $1.5 \mathrm{~mL}$ of $20 \%$ sodium carbonate followed by a vigorous mixing. Gallic acid in different concentrations was used as a reference standard. Finally, the prepared solution was incubated in dark for $2 \mathrm{~h}$ and absorbance was recorded at $765 \mathrm{~nm}$ against blank using UV spectrometer. The total phenolic content was expressed in terms of $\mathrm{mg} / \mathrm{g}$ gallic acid equivalent.

\section{Estimation of total flavonoid content}

The colorimetric method, was used for determination of flavonoid content. Extract $(10 \mathrm{mg} / \mathrm{mL})$ in methanol was transferred in test tube containing $20 \%$ aluminum trichloride, followed by addition of few drops of acetic acid and further diluted with methanol up to $5 \mathrm{~mL}$. The absorption was taken at $415 \mathrm{~nm}$ after $40 \mathrm{~min}$ incubation in dark. Blank was prepared using same method except the incorporation of extract. The absorption of standard rutin solution $(0.5 \mathrm{mg} / \mathrm{mL})$ in methanol was measured under the same conditions which were used for extract. The amount of flavonoids in sample was calculated as $\mathrm{mg} / \mathrm{g}$ rutin equivalent, using formula: $\mathrm{X}=\left(\mathrm{A} . \mathrm{m}_{\mathrm{o}}\right) /\left(\mathrm{A}_{\mathrm{o}} \cdot \mathrm{m}\right)$, where $\mathrm{X}$ is the flavonoid content, $\mathrm{mg} / \mathrm{g}$ sample in RE, $\mathrm{A}$ is the absorbance of sample solution, Ao is the absorbance of standard rutin solution, $\mathrm{m}$ is the weight of sample in $\mathrm{mg}$ and $m_{a}$ is the weight of rutin in the solution in $\mathrm{mg} .{ }^{[11]}$

\section{Fractionation}

Liquid-liquid partitioning method was used for fractionation. About $10 \mathrm{~g}$ extract was dissolved in $200 \mathrm{ml}$ of water and sonicated three times for $25-30 \mathrm{~min}$. Further the solution was transferred in separating funnel and allowed to set for $10 \mathrm{~min}$. n-Hexane $25 \mathrm{ml}$ was placed in separating funnel containing extract, slowly tilted upside down for 100 times and allowed to set. Color in n-hexane layer indicated separation of compounds. The colored fraction was placed in preweighed petri plate. The procedure was repeated till $n$-hexane layer became transparent. The method was repeated for chloroform and ethyl acetate Figure 3. Eventually, the remaining water fraction was filtered with Whatman filter paper and evaporated till dryness to derive water fraction. ${ }^{[12]}$

\section{HPLC}

\section{Chemicals}

Standard quercetin was purchased from Sigma Mumbai. The solvents used were of HPLC grade.

\section{Preparation of standard solution}

Accurately weighed $10 \mathrm{mg}$ of quercetin placed in $10 \mathrm{ml}$ volumetric flask was dissolved in small portion of methanol and volume was made up to $10 \mathrm{ml}$ (1000 ppm stock solution). Further, $1 \mathrm{ml}$ of stock solution was diluted with $10 \mathrm{ml}$ methanol, to get final concentration of $100 \mathrm{ppm}$.

\section{Preparation of test solution}

The test solutions of extract and fractions (100 ppm) were prepared using same method as that for standard.

\section{Instrumentation}

The HPLC chromatographic studies were performed by reversed phase HPLC UV method using an isocratic elution. The system composed of a LC-20AD pump, a SPD-M20A diode array detector (Shimadzu, Japan), a reverse phase PrincetonSPHER-100 $\mathrm{C}_{18}$ column $(250 \mathrm{~mm} \times 4.6 \mathrm{~mm}$, $5 \mu \mathrm{m}$ particle size) operated by LC-Solution data acquisition software. The mobile phase used was acetonitrile and $2 \% \mathrm{v} / \mathrm{v}$ acetic acid $(\mathrm{pH} 2.60)$ (40\%: $60 \% \mathrm{v} / \mathrm{v}$ ) with flow rate $1.3 \mathrm{~mL} / \mathrm{min}, 35^{\circ} \mathrm{C}$ column temperature and detection was done at $370 \mathrm{~nm}$ Table 4 .

\section{Procedure}

The standard solution and prepared solution were injected one after the other using Hamilton syringe and chromatogram were recorded on set parameters.

\section{RESULTS AND DISCUSSION}

Biologically active compounds are present at very low concentration in plants. Proper extraction methods cause less damage to the functional properties of phytoconstituents and ease better yield. ${ }^{[13]}$ The aqueous ethanolic maceration gives better yield with no damage to the thermo labile components. The Table 1 represents the percent yield of extracts and fractions. The percent yield is the ratio of the weight in grams of extract to the weight of powdered drug taken, multiplied by $100{ }^{[13]}$ The preliminary phytochemical screening of aqueous ethanolic extract of P. murex fruits revealed the presence of alkaloids, saponins, tannins, flavonoids, sugar, glycosides, phenols and sterols ${ }^{[14]}$ Table 2. Figure 1 and 2 shows the calibration curve of gallic acid and quercetin. The total phenolic content determined using linear regression equation $(\mathrm{y}=$

\section{Table 1: Percent yield.}

\begin{tabular}{|c|c|c|}
\hline Sr.no. & Extract/fraction & Percent yield \\
\hline 1 & Aqueous ethanolic extract & $2.8 \%$ \\
\hline 2 & n-Hexane & $0.76 \%$ \\
\hline 3 & Chloroform & $0.38 \%$ \\
\hline 4 & Ethylacetate & $0.43 \%$ \\
\hline 5 & Aqueous & $1.4 \%$ \\
\hline
\end{tabular}

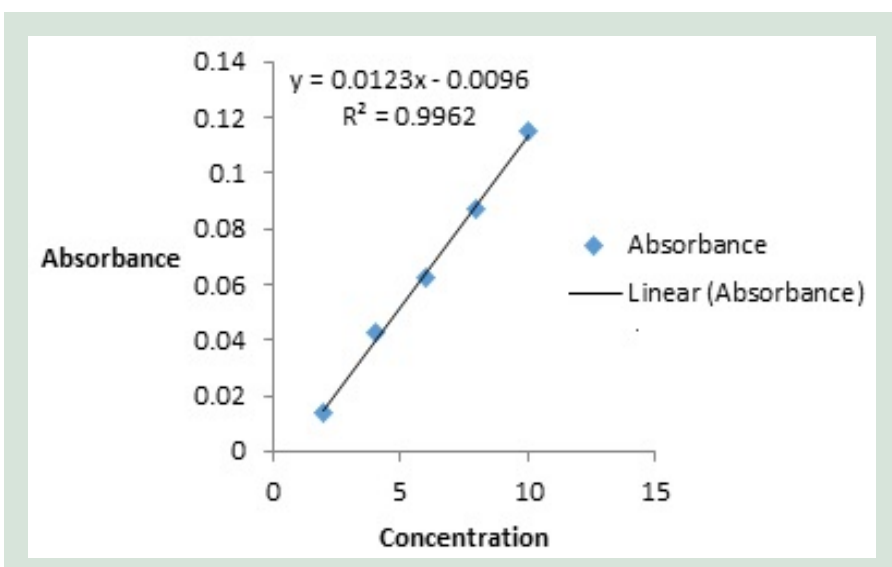

Figure 1: Calibration curve for standard gallic acid. 
Table 2: Phytochemical analysis of aqueous ethanolic extract.

\begin{tabular}{|c|c|c|c|c|}
\hline Sr.no & Phytoconstituents & Test & Observation & Inference \\
\hline \multirow[t]{2}{*}{1.} & Sterols & Salkowski & + & \multirow{2}{*}{ Sterols present } \\
\hline & & Lieberman burchard & + & \\
\hline \multirow[t]{4}{*}{2.} & Alkaloids & Dragendorff"s reagent & + & \multirow{4}{*}{ Alkaloids present } \\
\hline & & Mayer's reagent & + & \\
\hline & & Wagner's reagent & + & \\
\hline & & Hager's reagent & + & \\
\hline 3. & Saponins & Foam test & + & Saponins present \\
\hline \multirow[t]{2}{*}{4.} & Tannins & Ferric chloride test & + & \multirow{2}{*}{ Tannins present } \\
\hline & & Lead acetate test & + & \\
\hline 5. & Flavonoids & Shinoda test & + & Flavonoids present \\
\hline \multirow[t]{2}{*}{6.} & Sugars & Molisch's test & + & \multirow{2}{*}{ Sugars present } \\
\hline & & Barfoed's test & + & \\
\hline \multirow[t]{2}{*}{7.} & Proteins & Biuret test & - & \multirow{2}{*}{ Proteins absent } \\
\hline & & Xanthoproteic test & - & \\
\hline 8. & Amino acid & Ninhydrin test & - & Amino acids absent \\
\hline 9. & Glycosides & Sodium hydroxide test & + & Glycosides present \\
\hline 10. & Phenols & Ferric chloride test & + & Phenols present \\
\hline
\end{tabular}

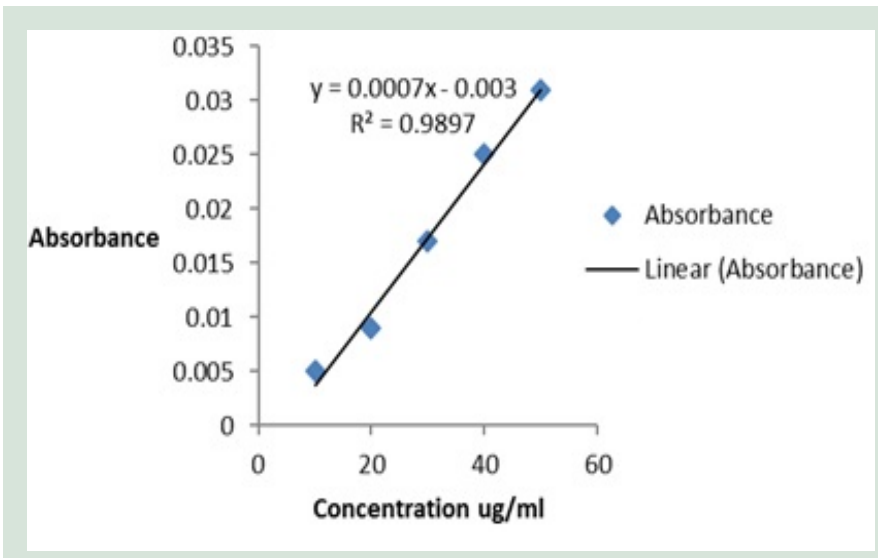

Figure 2: Calibration curve for standard Quercetin.

Table 3: Estimation of total phenolic, flavonoids content of $P$. murex fruit. ${ }^{[12]}$

\begin{tabular}{|c|c|c|}
\hline Sr.no. & Estimations & Hydroalcoholic extract of P.murex \\
\hline 1. & Phenolic content & $27.1 \pm 0.72 \mathrm{mg} / \mathrm{g}$ equivalent of gallic acid \\
\hline 2. & Flavonoids content & $17.6 \pm 0.79 \mathrm{mg} / \mathrm{g}$ equivalent of quercetin \\
\hline
\end{tabular}

Values are mean of triplicate determination $(n=3) \pm$ standard deviation

$0.0123 \mathrm{x}-0.0096 R^{2}=0.9962, R^{2}$ represents correlation coefficient) was found to be $27.1 \pm 0.72 \mathrm{mg} / \mathrm{g}$ equivalent of gallic acid while the flavonoid content was expressed as $17.6 \pm 0.79 \mathrm{mg} / \mathrm{g}$ equivalent of quercetin Table $3 .^{[15]}$ Standardization of herbal drugs is a matter of interest and concern for herbal drug industry. ${ }^{[16]}$ The quality of drugs may get affected due to parameters like harvesting, storage, processing methods, adulterants as well as during preparation of formulation. Herbal drugs are unacceptable unless they are properly characterized and authenticated. ${ }^{[17]}$ With the emergence of new trends in chromatographic techniques it is possible to produce rapid, easy, accurate, cost effective and reproducible methods for standardization. ${ }^{[18,19]}$ High performance liquid chromatography [HPLC] is highly sensitive method used for quality assessment of herbal drugs,

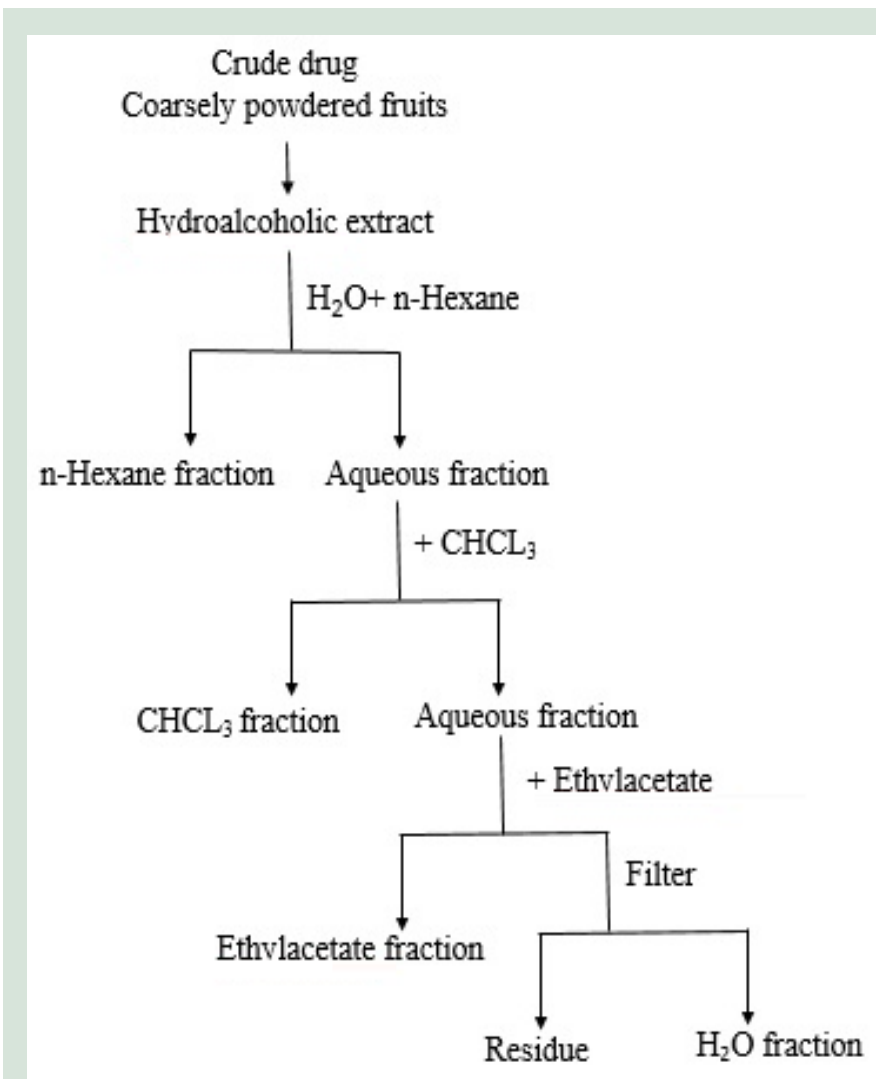

Figure 3: Fractionation using liquid-liquid partitioning.

extracts, products and formulations. ${ }^{[20,21]}$ Flavonoids are the major secondary metabolites present in P. murex. Figure 4. Represents the chromatogram of standard drug quercetin with retention time 4.094 at $370 \mathrm{~nm}$. The retention peaks were considered for standardization of extract and fractions. The whole aqueous ethanolic extract and fractions including n-hexane, chloroform and ethylacetate revealed presence of multiple peaks at variable retention time which confirms the presence 


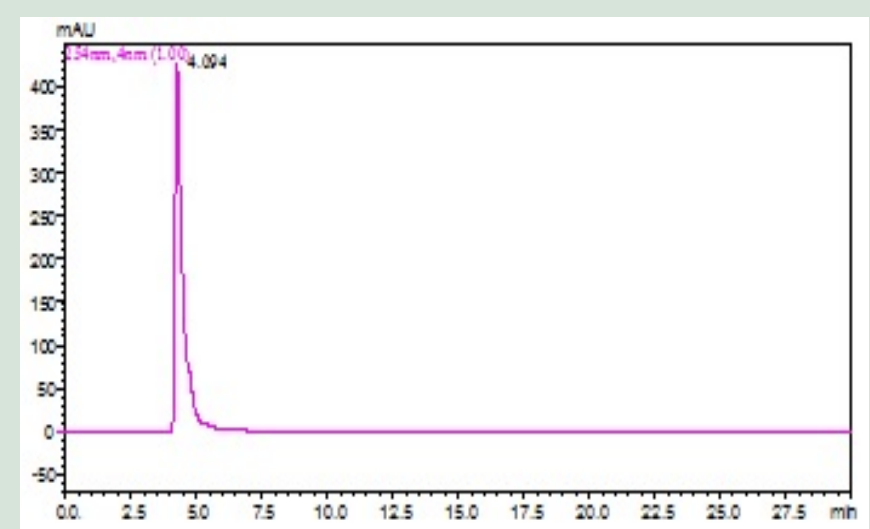

Figure 4: Chromatogram of Standard Quercetin.

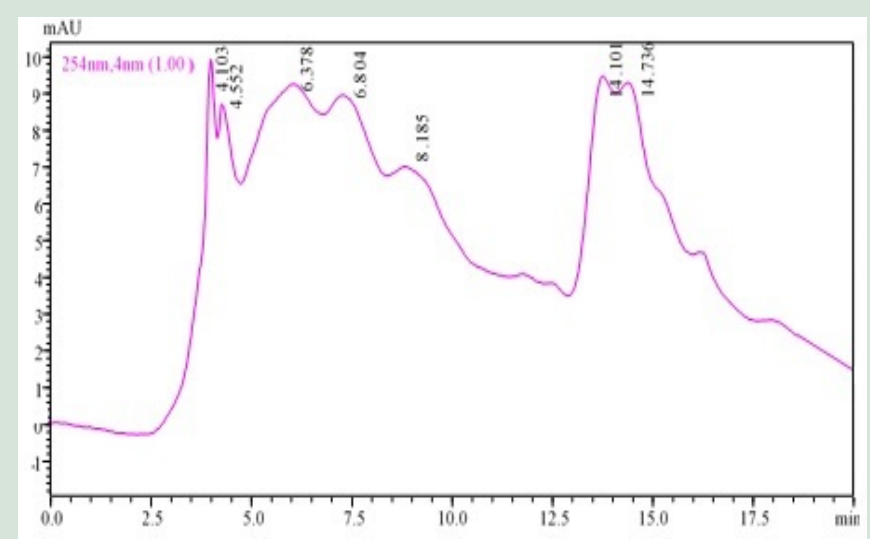

Figure 5: Chromatogram of Mother extract.

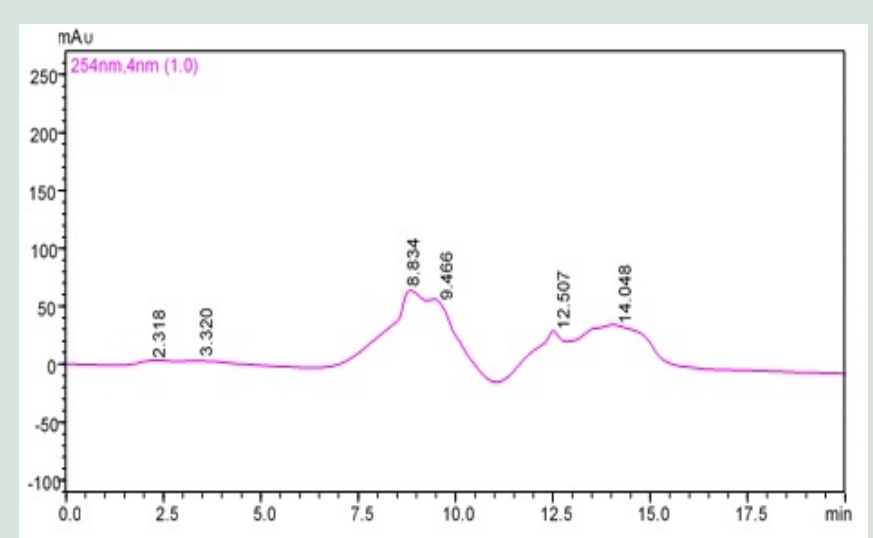

Figure 6: Chromatogram of $n$-Hexane fraction.

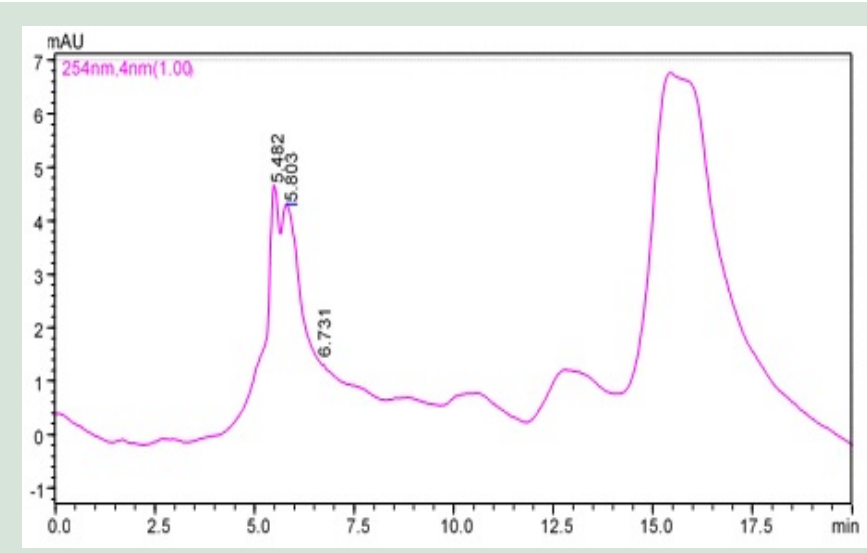

Figure 7: Chromatogram of Chloroform fraction.

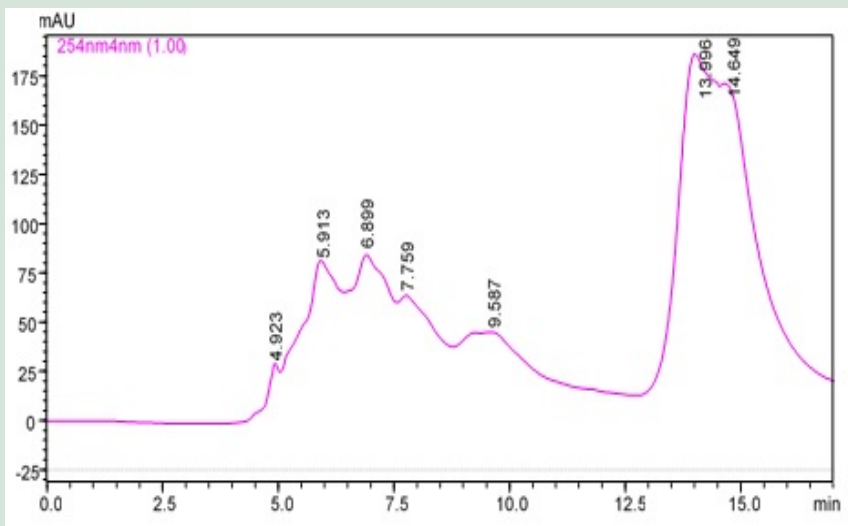

Figure 8: Chromatogram of Ethylacetate fraction.

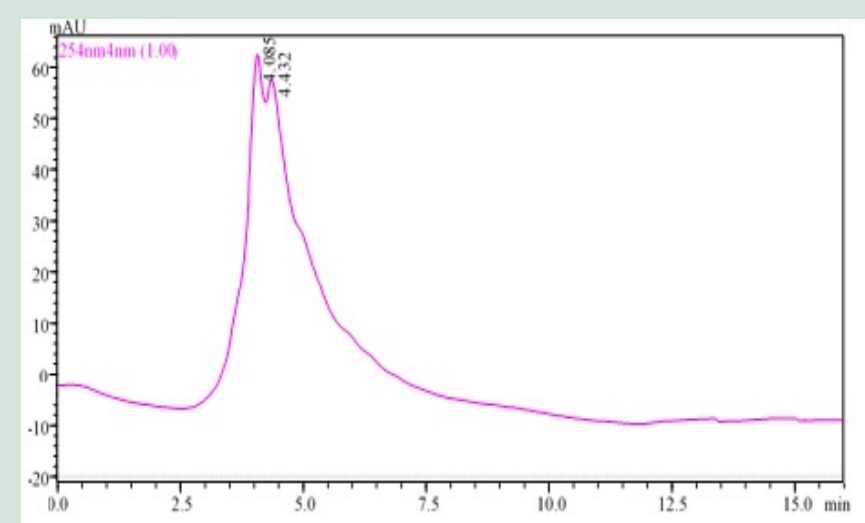

Figure 9: Chromatogram of aqueous fraction. 
Table 4: HPLC parameters for standardization.

\begin{tabular}{|c|c|c|}
\hline Sr. no. & Variables & Conditions \\
\hline 1. & Marker & Quercetin \\
\hline 2 & Mobile Phase & $\begin{array}{c}\text { Acetonitrile: Acetic acid }(2 \% \\
\text { V/V) }(40: 60) \mathrm{PH} 2.6\end{array}$ \\
\hline 3 & Wavelength $(\mathrm{nm})$ of & $370 \mathrm{~nm}$ \\
\hline 4 & Detection & $1.3 \mathrm{ml} / \mathrm{min}$ \\
\hline 5 & Flow rate & $35^{\circ} \mathrm{C}$ \\
\hline
\end{tabular}

of variable phytoconstituents Figures 5-8. The water fraction revealed peak at retention time $4.085,4.432$, which complement with the chromatogram of standard quercetin addressing presence of quercetin Figure 9. ${ }^{[22]}$

\section{CONCLUSION}

Phytochemical assessment of plant is an important parameter which gives the basic idea of the secondary metabolites present in the variable parts of plant. Therefore, it is requisite to perform the analysis according to the standard procedures mentioned. However, HPLC is the advent in the chromatographic investigations which simplifies the qualitative and quantitative studies of herbal extracts and allows detection of variable compounds in extracts. Thus, the present study provides the phytochemical profile of the $P$. murex extract and also confirmed the presence of quercetin in its different fractions along with the mother extract.

\section{ACKNOWLEDGEMENT}

The authors would like to acknowledge Department of Pharmaceutical Sciences, R.T.M. Nagpur University, Nagpur for providing the necessary facilities to carry out the study.

\section{CONFLICT OF INTEREST}

The authors declare no conflict of interest.

\section{ABBREVIATIONS}

$\boldsymbol{R}^{2}$ : Correlation coefficient; $\mathbf{m g} / \mathbf{g}:$ Milligram/Gram; w/w: Weight by weight; mg: Milligram; mL: Milliliter; N: Normal; nm: Nanometer; mg/mL: Milligram/ Milliliter; Min: Minute; h: Hour; A: Absorbance of sample solution; mo: Weight of Rutin in the solution in mg; Ao: Absorbance of standard Rutin solution; m: Weight of sample in mg; HPLC: High performance liquid chromatography; ppm: Parts per million; UV: Ultraviolet; Mm: Millimeter; $\mu \mathrm{m}$ : Microgram; v/v: Volume by volume; $\mathbf{m L} / \mathbf{m i n}$ : Millilitre/minute; C: Celsius; +: Present; -: Absent; $\mu \mathrm{m} / \mathrm{mL}:$ Microgram/milliliter; $\mathbf{C H C l}_{3}$ : chloroform.

\section{REFERENCES}

1. Devanesan AA, Zipora T, Smilin G, Aseervatham B, et al. Phytochemical and pharmacological status of indigenous medicinal plant Pedalium murex L.: A review. Biomedicine and Pharmacotherapy. 2018;103:1456-63.

2. Patel D, Laloo D, Kumar R, Hemalatha S. Pedalium murex Linn.: An overview of its phytopharmacological aspects. Asian Pacific Journal of Tropical Medicine. 2011;4(9):748-55

3. Arya Vaidya Sala. Indian medicinal plants a compendium of 500 species. Coll No AVS. 1692;230.

4. Chaudhary G, Kaushik N. Phytochemical and pharmacological studies in Pedalium murex L. Phytochem Rev. 2017:16(5):921-34. Available form DOI 10.1007/s11101-017-9499-z

5. Nadkarni K. Medicinal plants of India. Reprinted publication Dehradun India. Indian Plants and Drugs. 1980;289-90.

6. Kirtikar K, Basu B. Indian Medicinal Plants. IInd edition. 1935;6:1856-57.

7. Elumalai L, Eswaraiah C, Naresh M, Sudheer V, Mandala N. A review on therapeutic uses of Pedalium murex Linn. IJRAP. 2011;2(6):1743-5.

8. Rajashekar E, Upender R, Srinivas P. Biological activities and medicinal properties of Gokhru (Pedalium murex L.). Asian Pacific Journal of Tropical Biomedicine. 2012;2(7):581-5

9. Kothari V, Gupta A, Naraniwal M. Extraction methods for preparation of bioactive plant extracts: A comparative study. Publisher: Lambert Academic Publishing (LAP), Germany. 2012;20-30.

10. Sermakkani M, Thangapandian V. Phytochemical screening for active compounds in Pedalium murex L. Recent Research in Science and Technology. 2010;2(1):110-4

11. Harborne J. Phytochemical methods. A Guide to Modern Techniques of plant analysis. Chapman and Hall, London. 1973.

12. Patel D, Kumar R, Prasad S, Hemalatha S. Pedalium murex Linn (Pedaliaceae) fruits: A comparative antioxidant activity of its different fractions. Asian Pacific Journal of Tropical Biomedicine. 2011;1(5):395-400.

13. Selvamani P, Sen D, Gupta J. Pharmacognostical standardization of Commiphora berryi (Arn) Engl and phytochemical studies on its crude extracts. African $J$ Pharma Pharmacol. 2009;3(2):37-46.

14. Dhanani T, Shah S, Gajbhiye N, Kumar S. Effect of extraction methods on yield, phytochemical constituents and antioxidant activity of Withania somnifera Arabian. Journal of Chemistry. 2017;10(1):S1193-9.

15. Kokate C. Practical Pharmacognosy. $4^{\text {th }}$ edition. Delhi: Vallabh Prakashan. 1994.

16. Yang C, Zhao J, Cheng Y, Li X, Rong J. Bioactivity-Guided Fractionation Identifies Amygdalin as a Potent Neurotrophic Agent from Herbal Medicine Semen Persicae Extract. Bio Med Research International. 2014. Available form DOI 10.1155/2014/306857

17. Shi P, Du W, Wang Y, Teng X, Chen X, Ye L. Total phenolic, flavonoid content and antioxidant activity of bulbs, leaves and flowers made from Eleutherine bulbosa (Mill.). Urb Food Sci Nutr. 2019;7(1):148-54.

18. Shivarkar R, Bhise S, Rama V, Gupta M. Standardization and quantification of curcumin present in Curcuma Longa extract using HPLC. International Journal of Phytopharmacology. 2017;8(3):117-22.

19. Upadhyay V, Sharma N, Tiwari A, Joshi H, Malik A, Singh B, et al. Standardization of HPLC Method of Scopoletin in Different Extracts of Convolvulus pluricaulis. International Journal of Pharmaceutical Sciences and Drug Research. 2013;5(1):28-31

20. Muti H, Olimat S. HPLC Method of Analysis for Determination and Standardization of Luteolin and Vanillic acid in Dry Extract of Paronychia argentea Lam. Orient J Chem. 2018;34(6):2721-7.

21. Acharya R, Sharma B, Singh R, Jain P. Phytochemical and High-Performance Liquid Chromatography Analysis of Extract of Vernonia cinerea. Journal of Drug Delivery and Therapeutics. 2019;9(1):229-32

22. Srinivas K, King J, Howard L, Monrad J. Solubility and solution thermodynamic properties of quercetin and quercetin dihydrate in subcritical water. Journal of Food Engineering. 2010;100(2):208-18 


\section{GRAPHICAL ABSTRACT}

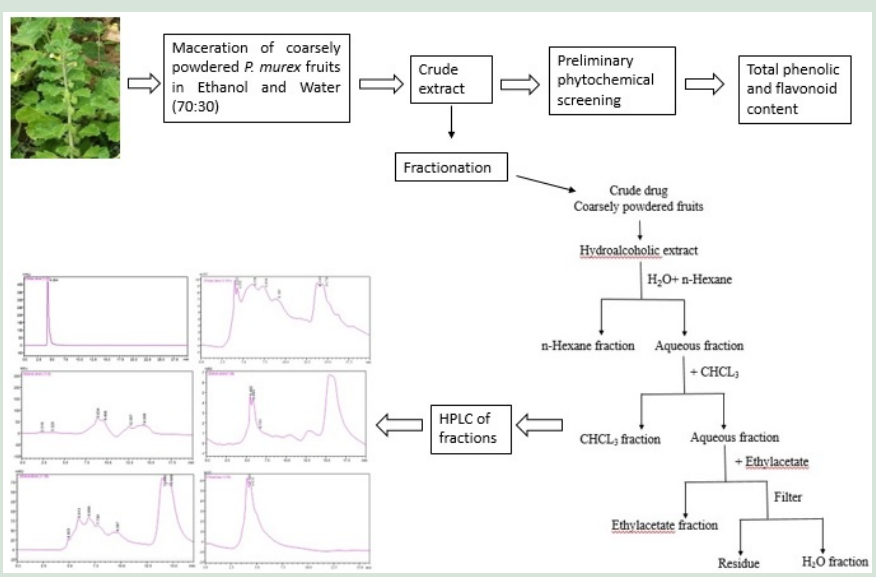

\section{SUMMARY}

The present work deals with the development of phytochemical profile and the standardization of crude extract of Pedalium murex fruits with the help of most effective, sensitive, easy and accurate high performance liquid chromatographic technique (HPLC). The work performed includes extraction, phytochemical analy sis, estimation of total phenolic and flavonoid content followed by fractionation of crude extract with the series of solvent viz. n-hexane, chloroform, ethylacetate and water. The HPLC studies of mother extract and fractions were carried out. The preliminary phytochemical screening revealed the presence of variety of phytoconstituents. The total phenolic content was found to be $27.1 \pm 0.72 \mathrm{mg} / \mathrm{g}$ equivalent of gallic acid while the flavonoid content was expressed as $17.6 \pm$ $0.79 \mathrm{mg} / \mathrm{g}$ equivalent of quercetin. The mother extract and the aqueous fraction revealed peaks complementary with the chromatogram of standard quercetin addressing presence of quercetin. Standardization of herbal drugs being a matter of interest and concern for herbal drug industry, the method was found to be most reliable and reproductive.

\section{ABOUT AUTHORS}

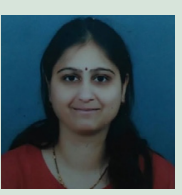

Mrs. Renuka K. Mahajan is a doctoral student at the Department of Pharmaceutical Sciences, Rashtrasant Tukadoji Maharaj Nagpur University, Nagpur, Maharashtra, from where she has completed her Bachelors and Master's degree. Her doctoral research is focused on Development and Evaluation of Polyherbal Formulations for its Pharmacognostic and Pharmacological Potential Against Diabetic Nephropathy.

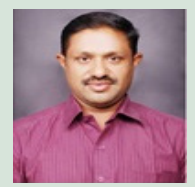

Dr. Prakash R. Itankar, is a Professor at the Department of Pharmaceutical sciences, Rashtrasant Tukadoji Maharaj Nagpur University, Nagpur, Maharashtra. His area of expertise is validation of medicinal plants, ethno pharmacology, validation of Panchagavya Ayurvedic Chikitsa, patents and publications. He has projects in collaboration with MODROB, AICTE, and NMPB. He is experienced in the field of Pharmacognosy and Phytochemistry of natural products mainly in medicinal plants.

History: Submission Date: 31-10-2020; Review Completed: 11-12-2020; Accepted Date: 28-01-2021

Cite this article: Mahajan R, Itankar P. Phytochemical Analysis and Standardization of Pedalium murex Linn. Extract through HPLC Methods. Indian J Nat Prod. 2021;35(1):32-7. 